\title{
Facts about Copper ${ }^{1}$
}

Linda B. Bobroff ${ }^{2}$

\section{Why do we need copper?}

Copper is one of the trace minerals we need in our diet. It helps keep the body tissues healthy and is needed

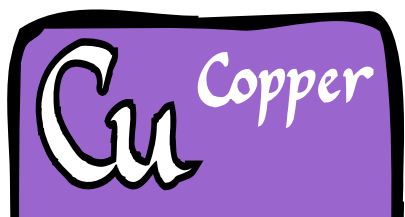
for proper use of iron in the body. Copper also is involved in antioxidant function. Atomic Number: 29 Atomic Mass: 63.55 This trace mineral helps keep the immune system, nervous system, and

heart healthy.

\section{What happens if we don't get enough copper?}

Copper deficiency is rare, but can occur in some conditions. Copper deficiency has been seen in pre-term infants who were fed milk formulas. Copper

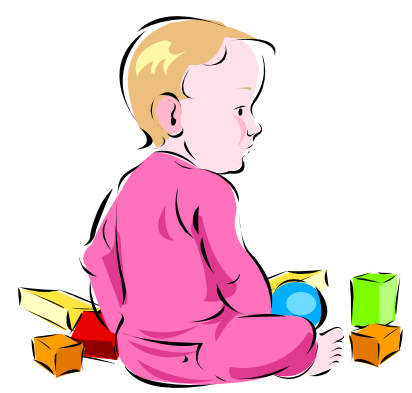
deficiency also can occur in people fed only through their veins for a long time (total parenteral nutrition).
Copper deficiency causes anemia, low white blood cell counts, and low bone density. Low intake during pregnancy may cause birth defects. High intake of iron or zinc can decrease copper absorption and cause a deficiency. It is best to get these minerals from foods we eat rather than supplements.

\section{How much copper do we need?}

The following table lists recommended daily intakes of copper. There is no difference in the amount needed by men and women, except when a woman is pregnant or breastfeeding.

\begin{tabular}{|l|c|}
\hline \multicolumn{1}{|c|}{ Life Stage } & $\begin{array}{c}\text { Copper } \\
\text { (mcg/day) }\end{array}$ \\
\hline Men, ages 19+ & 900 \\
\hline Women, ages, 19+ & 900 \\
\hline Pregnancy & 1000 \\
\hline Breastfeeding & 1300 \\
\hline mcg = micrograms & \\
\hline
\end{tabular}

1. This document is FCS8804, one of a series of the Department of Family, Youth and Community Sciences, Florida Cooperative Extension Service, Institute of Food and Agricultural Sciences, University of Florida. Revised: June 2008. Please visit the EDIS Web site at http://edis.ifas.ufl.edu.

2. Linda B. Bobroff, PhD, RD, LD/N, professor, Department of Family, Youth, and Community Sciences, Cooperative Extension Service, Institute of Food and Agricultural Sciences, University of Florida, Gainesville, FL 32611. 


\section{How can we get enough copper?}

Shellfish and organ meats like liver are excellent sources of copper. Nuts and seeds, mushrooms, whole grain cereals, and legumes contain some copper.
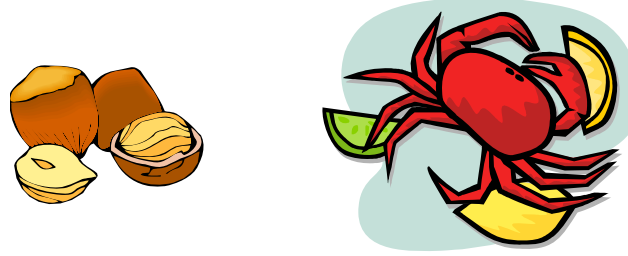

Here are some foods and the amount of copper they contain:

\begin{tabular}{|lc||}
\hline \multicolumn{1}{|c|}{ Food } & $\begin{array}{c}\text { Copper } \\
\text { (mcg/serving) }\end{array}$ \\
\hline \hline Beef Liver, cooked, 3 ounces & 3830 \\
Oysters, cooked, 3 ounces & 640 \\
Baked beans, vegetarian, canned, & 520 \\
1 cup & 510 \\
Sunflower seeds, oil roasted 1 & 420 \\
ounce & 390 \\
Refried beans, canned, 1 cup & 360 \\
Mushrooms, cooked, 1/2 cup & 350 \\
Peanuts, oil roasted, 1 ounce & 340 \\
Soy milk, 1 cup & 300 \\
Pecans, oil roasted, 1 ounce & 270 \\
Tofu, firm, 1/2 cup & 240 \\
100\% Bran Cereal, 1 ounce & 210 \\
Sweet potato, baked, medium & 200 \\
Casava, raw, 1 cup & 140 \\
Baked potato, 1 medium & 70 \\
Beef chuck roast, 3 ounces & \\
Ground beef, broiled patty, 3 & \\
\hline ounces & \\
\hline mcg = micrograms & \\
\hline
\end{tabular}

Breastfed infants get more copper than those fed formula.

\section{What about supplements?}

Most Americans get all the copper they need from the foods they eat. Supplements are not generally needed. Taking a multivitamin or mineral supplement with no more than the recommended daily intake is fine.

\section{How much is too much?}

Copper toxicity is rare in healthy people. However, very high intakes over time can cause liver damage. Keep your total copper intake less than $10,000 \mathrm{mcg}$ (10 $\mathrm{mg})$ per day from food and supplements combined.

\section{Where can I get more information?}

The Family and Consumer Sciences (FCS) agent at your county Extension office may have more written information and nutrition classes for you to attend. Also, a registered dietitian (RD) can provide reliable information to you.

Reliable nutrition information may be found on the Internet at the following sites:

http://solutionsforyourlife.ufl.edu http://www.nal.usda.gov/fnic http://www.nutrition.gov http://www.mayohealth.org 
Filename: $\quad$ FY1038 - FCS8804 Facts about Copper

Directory: $\quad$ C: $\quad$ Documents and Settings $\backslash$ tprescott $\backslash$ My Documents

Template: IIfycs-server|public।WordTemplate\\#\#authorWORDtemplate.dot

Title:

Subject:

Author: $\quad$ Linda Bobroff

Keywords:

Comments:

Creation Date: $\quad$ 7/10/2008 5:20:00 PM

Change Number: 2

Last Saved On: $\quad$ 7/10/2008 5:20:00 PM

Last Saved By: tprescott

Total Editing Time: 1 Minute

Last Printed On: $\quad$ 7/10/2008 5:20:00 PM

As of Last Complete Printing

Number of Pages: 2

Number of Words: 493 (approx.)

Number of Characters: $\quad 2,407$ (approx.) 